\title{
RNA extraction optimization from dengue- infected clinical residual serum using laboratory prepared reagent
}

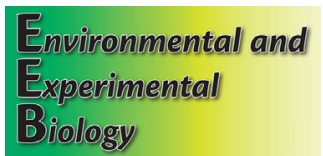

ISSN 2255-9582

UNIVERSITY OF LATVIA

\author{
Sowrabha Ramachandra', Aayushi Randhawa', \\ Chandrakanth Kelmani², Sathyanarayan Muthur Shankar ${ }^{3}$, \\ Manjulakumari Doddamane ${ }^{1 *}$
}

\author{
${ }^{1}$ Department of Microbiology and Biotechnology, Bangalore University, Bengaluru, Karnataka, India \\ ${ }^{2}$ Department of Biotechnology, Gulbarga University, Kalburgi, Karnataka, India \\ ${ }^{3}$ Department of Microbiology, Bangalore Medical College and Research Institute, Victoria Hospital \\ Campus, Bengaluru, Karnataka, India \\ ${ }^{\star}$ Corresponding author, E-mail: manjulakumari_doddamane@yahoo.co.in
}

\begin{abstract}
In RNA isolation protocol, two essential factors decide the quality of RNA. One is an extra care of avoiding effect of omnipresent ribonucleases using potent inhibitors such as guanidine isothiocyanate (GITC). The other is the extraction reagent's chemical combination and concentration, which is decided based on the source sample of RNA. In virus-infected clinical samples, the extraction efficiency relies on the aetiologic agent's titre value, which is dependent on the day of sample collection from the onset of the disease. The quality of RNA is crucial for accurate diagnosis and other downstream applications. Dengue, a flaviviral infection, displays a high titre and becomes desirable for molecular diagnosis. Here we optimized viral RNA isolation from dengue-infected NS1 (nonstructural protein) positive residual clinical serum samples based on the original GITC-phenol-chloroform extraction method. A concentrated RNA extracting reagent called REC reagent was defined and used along with the glycogen carrier. This laboratory-prepared reagent and glycogen as co-precipitant aided in better isolation of RNA. Glycogen also contributed to the visibility of the pellet, which helped to process the washing step efficiently. This methodology is cost-effective in a research laboratory setup against a commercial kit, especially when a vast number of specimens are involved. The manual methods give scope for modifications, thus bringing down the cost. The challenges connected to the usage of residual samples and the methodology is discussed in detail.
\end{abstract}

Key words: clinical residual serum, dengue, GITC-phenol-chloroform extraction method, glycogen carrier, REC reagent, RNA isolation. Abbreviations: DENV, dengue virus; DEPC, diethyl pyrocarbonate; GITC, guanidine isothiocyanate; NS1, nonstructural protein; qRTPCR, quantitative real-time reverse transcriptase polymerase chain reaction; REC reagent, RNA extracting concentrated reagent; RNase, ribonuclease.

\section{Introduction}

Viruses, among other pathogens, stand out due to their unique nature in occurrence and mode of infection (Woolhouse et al. 2012). Viruses with a RNA genome have the highest adaptability to changes in the host immunity levels through rapid mutations and represent the biggest group of emerging or re-emerging pathogens (Howard, Fletcher 2012). The flaviviruses, a group of RNA viruses, were the first among discovered viruses known to infect humans (Woolhouse et al. 2012). Dengue, one such flavivirus, has now established itself and has become the world's concern (Pekosz, Glass 2008).

Being a neglected tropical disease, dengue is the fastest growing mosquito-transmitted infection, affecting the young population like children, with severe sickness and even death (Mukhtar 2015). Earlier up to 1970, the number of nations that had experienced epidemics of severe dengue was only nine, but now the disease has spread to over 100 countries (Brady et al. 2012; Bhatt et al. 2013). The World Health Organization estimates that 50 to 100 million dengue infections occur worldwide every year (Brady et al. 2012; Bhatt et al. 2013; Brady 2019).

Four serotypes of dengue virus (DENV), which are in close relation to each other, have been identified as DENV1, DENV-2, DENV-3, and DENV-4 (Domingo et al. 2011). In a few parts of the world, not only one type of flavivirus is endemic; hence higher probability of multiple and sequential infections by more than one type of flavivirus are expected (Halstead 1970). The sharing of similar epitopes by the $\mathrm{E}$ (envelop) protein among flaviviruses is responsible for their cross-reactivity (Aguado et al. 2019; Rathore, John 2020), which is observed frequently during their detection. The inability of serological tests to distinguish between the 
serotypes of the DENV limits their use in clinical practice. The laboratory diagnosis is obligatory for identifying the infectious agent due to the non-reliable common symptoms presented by different flaviviral infections (Patel et al. 2013).

Molecular diagnostics is the intrinsic component of today's clinical diagnosis (Mohamed 2006). An accurate diagnosis of dengue disease can be done during the acute phase of the infection, viremia, and fever phases (Peeling et al. 2010). Diagnostic tools currently used to detect DENV are virus isolation, capture IgM ELISA, capture IgG ELISA, quantitative real-time reverse transcriptase polymerase chain reaction (qRT-PCR), and immunochromatography of the dengue NS1 (nonstructural protein) antigen (Darwish et al. 2015).

The nucleic acid-based detection methods used for flaviviruses depend and differ on the infecting flavivirus, because few flaviviruses, including dengue, show high titre viremia, and a few others may not be viremic or have undetectable viremia in infected human hosts (Tang et al. 1997). Thus, molecular diagnosis can be potentially used only for such aetiologic agents with high titre viremias, and dengue is one such flavivirus (Tang et al. 1997).

Dengue, as many other infections, can be classified into primary and secondary infections. The acute phase of the primary infection is characterized by the presence of virus as such, NS1 antigen and/or IgM or HI (hemagglutinationinhibiting) antibodies, and absence of IgG antibodies. On the contrary, during a secondary infection, high IgG levels are detectable even in the acute phase. Their level shows a dramatic rise over the next two weeks, and by then IgM will be at significantly low levels (Ganeshkumar et al. 2018).

Early detection of dengue infection is necessary to design proper treatment. Molecular methods for dengue detection are extensively being used for their specificity, accuracy, sensitivity, and rapidity (Mabey et al. 2004). To improve nucleic acid detection methods, routine studies on the genome of a pathogen are essential (Houldcroft et al. 2017).

Isolation of its positive-sense single-stranded RNA genome is a prerequisite and critical step in studying the dengue genome. The RNA isolation is basically modeled on the isolation of DNA, which was initiated in 1869 by a Swiss physician called Friedrich Miescher to explore the chemical fundamentals of life (Dahm 2004). This event paved the way for designing numerous molecular biology experiments. Now, several advanced methods to obtain pure DNA, RNA, or proteins are available. These methods could be broadly divided into two types, either solution-based or column-based (Tan, Yiap 2009). The basic steps in extraction protocol include effective cell lysis, denaturation of nucleoprotein complexes, inactivation of nucleic acid degrading enzymes (nucleases), and providing a contaminant-free environment throughout the extraction procedure (Doyle 1996).

The phenol-chloroform extraction method is most widely used for nucleic acids (Tan, Yiap 2009). Ullrich et al., in 1977, first showed the use of guanidine isothiocyanate (GITC) in RNA extraction. Chemically, RNA is highly unstable compared to DNA due to the presence of the 2' $\mathrm{OH}$ group in a ribose sugar moiety. In turn, this makes RNA susceptible for hydrolysis, and its single strand nature also adds to its sensitivity to mutagens (Brooks 1998). Apart from these, the ubiquitous presence of stable RNA degrading enzymes, ribonucleases (RNases), is the most dangerous enemy during RNA extraction. These enzymes are highly stable because they can get refolded following heat denaturation, and they do not require any co-factors for their activity (Doyle 1996); this makes RNA extraction difficult in normal conditions. Hence it is essential to provide a strong protein denaturant that can degrade RNase, and this role is played by a chaotropic agent called GITC (Ullrich et al. 1977).

In 1987, Chomczynski and Sacchi developed a singlestep RNA extraction method using GITC and phenolchloroform, and this was called guanidine thiocyanatephenol-chloroform extraction (Sambrook, Russel 2001). This reagent was later commercialized by the brand names TRIzol $^{\mathrm{TM}}$ or TRI ${ }^{\mathrm{TM}}$ Reagent. The idea behind this method is to separate DNA from RNA by using an acidic reagent that contains GITC, sodium acetate, phenol, and chloroform (Chomczynski, Sacchi 2006). Due to the acidic condition in the aqueous phase, the total RNA will be retained in the upper aqueous phase and DNA and proteins in the interphase or lower organic phase. The RNA in the aqueous phase will be precipitated by adding isopropanol (Sambrook, Russel 2001).

A need for designing a reagent for isolating low concentration or diluted RNA from liquid samples led to the development of TRIzol ${ }^{\mathrm{TM}}$ LS reagent, which is specially meant for liquid samples such as blood and virus preparations. The mixture of phenol, GITC, and a few other components which facilitate the isolation of RNA from a range of samples, forming a single-phase solution constitute this reagent. The maintenance of RNA integrity by suppressing the activity of RNase during homogenization of samples will be effectively taken care of by this reagent (https://www.interchem.fr/ft/D/DU1295. pdf). This method helps in high throughput processing of the samples and hence serves as advancement to the singlestep RNA isolation method developed by Chomcynski and Sacchi (1987).

The original TRIzol ${ }^{\mathrm{TM}}$ and TRIzol ${ }^{\mathrm{TM}}$ LS reagents share common composition but only differ in the concentration of components. TRIzol ${ }^{\mathrm{TM}}$ LS reagent is used in 3:1 ratio with the sample where TRIzol ${ }^{\mathrm{TM}}$ is used in 10:1 ratio (https://www.interchem.fr/ft/D/DU1295.pdf). Hence, this suggests that TRIzol ${ }^{\mathrm{TM}}$ LS is approximately three times more concentrated than the original TRIzol ${ }^{\mathrm{TM}}$; this allows the use of less volume of reagent in relation to sample volume. This more concentrated formula increases the lysis capability of the reagent, resulting in the isolation of highquality total RNA from liquid samples such as serum, virus 
preparations, and even complex biological fluids (TRIzol ${ }^{\mathrm{TM}}$ LS Reagent, Thermo Fisher Scientific).

TRIzol $^{\text {TM }}$ LS reagent is being used in studies for extracting a small amount of RNA from liquid samples (Reynes et al. 2003; Palmares et al. 2017). The extraction of RNA from sera containing different amounts of viral genomic RNA or titres of DENV with TRIzol ${ }^{\mathrm{TM}}$ LS in the presence of linear acrylamide (co-precipitant) has been reported to be efficient (Anwar et al. 2009).

Total RNA extraction from virus-infected human serum samples has been achieved in the past by employing routinely used GITC and TRIzol ${ }^{\mathrm{TM}}$ methods (Chomczynski, Sacchi 1987; Chomczynski, Mackey 1995), and few have used commercially available kits for isolation of RNA and also have compared these methods for identifying the better one (Klungthong et al. 2007; Xiang et al. 2001). All these methods have shown better results in different circumstances.

Extraction methods in the form of commercial kits generally reduce the time but increase the total cost (Margam et al. 2010). Therefore, it is necessary to evaluate whether the overall convenience of using commercial kits is greater than the added cost. QIAGEN ${ }^{\mathrm{TM}}$ viral RNA isolation kits are based on the RNA affinity to a silica membrane/gel (Chen et al. 2008). Most of the studies employ this kit for ease of use and less time-consuming (Neeraja et al. 2015; Dias et al. 2019; Tsai et al. 2019).

A study comparing two methods, the ChomczynskiSacchi and the QIAamp_UltraSens virus kit, for isolation of dengue viral RNA from infected plasma samples showed few advantages and disadvantages. RNA concentration was significantly higher and showed more sensitivity with less cost consumption in the former method. The latter method was easy to perform and took less time with more cost consumption. These outcomes encourage using the technique that is more inexpensive to purify viral RNA, especially in the developing countries (Dettogni, Louro 2010).

The present study focuses on RNA extraction optimization from dengue-infected residual/leftover human serum samples in a cost-effective, feasible, and efficient way to suit the research laboratory setup.

\section{Materials and methods}

\section{Sample collection and storage}

Dengue-infected NS1 positive acute phase human serum residual samples collected from diagnostic centres during the annual dengue season were used as a source for the extraction of viral RNA. This sample collection is considered a blindfold collection, as no patient information is known. The samples were collected in autoclaved screw-capped $2 \mathrm{~mL}$ cryovials, from diagnostic centres in Bengaluru, Karnataka, India, within 1 to 2 days of blood collection and infection detection, where samples were stored at $4{ }^{\circ} \mathrm{C}$. The temperature status-quo was maintained during transport from a collection centre to the lab, and they were stored at $-30^{\circ} \mathrm{C}$ in the lab till further use.

\section{Maintenance of RNase-free environment}

A RNase-free environment was provided during the isolation procedure by treating the consumables such as microcentrifuge tubes, microtips, etc., used in the procedure and the workspace, with $0.1 \%$ diethyl pyrocarbonate water.

\section{Optimization of RNA extraction}

Initially, the GITC (Chomczynski, Sacchi 1987) and TRI ${ }^{\mathrm{TM}}$ Reagent (Sigma) (Chomczynski, Mackey 1995) methods were employed for isolation of RNA with required modifications, and later was shifted to other methods. All of the methods used in this work were based on the original GITC-phenol-chloroform extraction method (Chomczynski, Sacchi 1987; Chomczynski, Sacchi 2006).

\section{GITC method: denaturation and phase separation}

Dengue NS1 positive serum samples $(250 \mu \mathrm{L})$ were treated with $1 \mathrm{~mL}$ of denaturing solution (GITC solution $-4 \mathrm{M}$ GITC, $25 \mathrm{mM}$ sodium citrate, $0.5 \% \mathrm{~N}$-Lauroyl sarcosine and $0.1 \mathrm{M} \beta$-mercaptoethanol) and $100 \mu \mathrm{L}$ of $2 \mathrm{M}$ sodium acetate ( $\mathrm{pH} 4.5)$ was added and mixed well by inverting. This was followed by the addition of $1 \mathrm{~mL}$ Tris-equilibrated phenol ( $\mathrm{pH} 4.5$ ) and mixing thoroughly by inverting, to permit complete dissociation of the nucleoprotein complex. Subsequently, chloroform/iso-amyl alcohol (49:1, $200 \mu \mathrm{L})$ was added and properly mixed by shaking vigorously for $10 \mathrm{~s}$ and the suspension incubated for $15 \mathrm{~min}$ at $4{ }^{\circ} \mathrm{C}$ and then centrifuged at $6000 \times \mathrm{g}$ and $4{ }^{\circ} \mathrm{C}$ for $20 \mathrm{~min}$. Following centrifugation, the mixture separates into a lower phenolchloroform phase, interphase, and upper aqueous phase. Due to acidic $\mathrm{pH}$, RNA remains exclusively in the aqueous phase. The upper aqueous phase was carefully aspirated and transferred to a new vial for precipitation. From the precipitation step, the protocol is more or less common for both the methods; hence it is described further.

\section{$T R I^{T M}$ reagent method: denaturation and phase separation}

The serum samples $(250 \mu \mathrm{L})$ were treated with $1 \mathrm{~mL}^{\text {TRI }}{ }^{\mathrm{TM}}$ reagent and vortexed for $3 \mathrm{~min}$. The mixture was incubated for $5 \mathrm{~min}$ at room temperature (around $28^{\circ} \mathrm{C}$ ). For the incubated mixture, $200 \mu \mathrm{L}$ of chloroform was added and mixed by vigorous shaking for $15 \mathrm{~s}$ and incubated at room temperature for 2 to $3 \mathrm{~min}$. The samples were centrifuged at not more than $13000 \times \mathrm{g}$ for $5 \mathrm{~min}$ at $4{ }^{\circ} \mathrm{C}$. The upper aqueous phase was transferred to a new vial.

\section{RNA precipitation}

The aqueous phase collected in both methods was subjected to precipitation. RNA was precipitated by adding $1 \mathrm{~mL}$ of $100 \%$ isopropanol (ice cold) and incubated in this mixture for $30 \mathrm{~min}$ at $-30{ }^{\circ} \mathrm{C}$, then centrifuged for $10 \mathrm{~min}$ at $4{ }^{\circ} \mathrm{C}$ and $6000 \times \mathrm{g}$ and the supernatant was discarded. The pellet was dissolved in $300 \mu \mathrm{L}$ denaturing solution and transferred 
into a $1.5 \mathrm{~mL}$ microcentrifuge tube and the precipitation step was repeated with $300 \mu \mathrm{L} 100 \%$ isopropanol (this step was excluded in the TRI ${ }^{\mathrm{TM}}$ Reagent method). The pellet was washed in $1 \mathrm{~mL}$ of $75 \%$ ethanol, vortexed, and incubated for 10 to $15 \mathrm{~min}$ at room temperature to dissolve residual amounts of guanidine content in the pellet and centrifuged for $5 \mathrm{~min}$ at $4{ }^{\circ} \mathrm{C}$ and $6000 \times \mathrm{g}$, and the supernatant was discarded. The pellet was air-dried at room temperature for 10 to $15 \mathrm{~min}$. Finally, the pellet was dissolved in $20 \mu \mathrm{L}$ of DEPC treated water.

Later, a modification was brought in the protocol by increasing the duration of incubation from $30 \mathrm{~min}$ to overnight for improving the precipitation of RNA isolating from serum samples (Dettogni, Louro, 2010). A reference standard (insect larva) was used in the protocol to eliminate experimental error during isolation by GITC and TRI ${ }^{\mathrm{TM}}$ reagent methods.

\section{RNA isolation using laboratory prepared REC reagent}

A reagent for extracting the viral RNA was prepared in the laboratory, based on commercially available TRIzol ${ }^{\text {TM }}$ reagent composition (https://postharvestcentral.com, homemade TRIzol ${ }^{\mathrm{TM}}$ reagent) with increased concentration of components. This reagent is termed as RNA extracting concentrated (REC) reagent. The components with their working concentration were as follows: $2.4 \mathrm{M}$ guanidine thiocyanate, $1.2 \mathrm{M}$ ammonium thiocyanate, and $0.3 \mathrm{M}$ sodium acetate (3 M stock, $\mathrm{pH} 4.5$ ), 15\% glycerol. These components were dissolved and the volume was adjusted with DEPC water and stored at $4{ }^{\circ} \mathrm{C}$ till use.

RNA isolation using laboratory prepared REC reagent was carried out according to the TRIzol ${ }^{\mathrm{TM}}$ LS (Invitrogen) method (TRIzol ${ }^{\text {TM }}$ LS "Reagent user guide") with required modifications. The infected serum sample $(250 \mu \mathrm{L})$ was mixed with $500 \mu \mathrm{L}$ REC reagent and $500 \mu \mathrm{L}$ Tris equilibrated phenol ( $\mathrm{pH} 4.5$ ). The sample was homogenized by pipetting up and down several times and incubated for $5 \mathrm{~min}$ followed by the addition of $200 \mu \mathrm{L}$ chloroform with 2 to $3 \mathrm{~min}$ incubation. The mixture was centrifuged for 15 min at $7000 \times \mathrm{g}$ and $4{ }^{\circ} \mathrm{C}$. The upper aqueous phase was carefully aspirated and taken into a new vial. The collected aqueous phase was mixed with $600 \mu \mathrm{L}$ isopropanol (ice cold) and left overnight for incubation at $-30{ }^{\circ} \mathrm{C}$. After incubation, it was centrifuged for $10 \mathrm{~min}$ at $7000 \times \mathrm{g}$ and 4 ${ }^{\circ} \mathrm{C}$, and the pellet was separated from the supernatant. The pellet was suspended in $1 \mathrm{~mL}$ of $75 \%$ ethanol and vortexed briefly, and then centrifuged for $5 \mathrm{~min}$ at $4000 \times \mathrm{g}$ and $4{ }^{\circ} \mathrm{C}$. The supernatant was discarded by aspirating, and the pellet was air-dried. The air-dried pellet was dissolved in $20 \mu \mathrm{L}$ of DEPC-treated water and incubated for 10 to $15 \mathrm{~min}$ at 55 to $60^{\circ} \mathrm{C}$.

\section{RNA isolation using a commercial kit}

The infected serum samples were subjected to RNA isolation procedure using the QIAamp Viral RNA Mini ${ }^{\text {TM }}$ kit (QIAGEN). The protocol was followed according to the manufacturer's instructions with slight modification by reducing the eluent volume to $20 \mu \mathrm{L}$, as not to dilute RNA in the extract. The elution step was carried out three times with $20 \mu \mathrm{L}$ of buffer AVE each time.

\section{RNA isolation using REC reagent with glycogen carrier}

RNA grade/molecular grade glycogen was prepared in the laboratory from glycogen of an oyster source (Himedia ${ }^{\mathrm{TM}}$ ). The glycogen (5\%) was dissolved in autoclaved Milli-Q water for about 2 to $3 \mathrm{~h}$ with constant stirring on a magnetic stirrer. Thus, dissolved glycogen was mixed thoroughly by vortexing with one volume of tris equilibrated phenol $(\mathrm{pH}$ 8.0 ) and centrifuged at $7000 \times g$ for $5 \mathrm{~min}$. The upper aqueous phase transferred to the clean vial was vortexed with one volume of 50:1 chloroform and isoamyl alcohol mixture (ice cold) and centrifuged. The upper aqueous phase thus obtained was treated with one volume of absolute ethanol to precipitate the glycogen and centrifuged. The glycogen pellet was air-dried for about 7 to $8 \mathrm{~h}$ till all the moisture was removed. The required concentration $\left(20 \mathrm{mg} \mathrm{mL}^{-1}\right)$ stock was prepared by dissolving the pellet with DEPCtreated water, and an $1 \mathrm{~mL}$ aliquot was stored at $4{ }^{\circ} \mathrm{C}$ for further use (Salvi 2004; Fan 2006).

In this method, the laboratory prepared REC reagent procedure, as described earlier, was followed for RNA isolation, except for the addition of glycogen as a carrier at a final concentration of $1 \mu \mathrm{g} \mu \mathrm{L}^{-1}$ and $1 \mu \mathrm{L}$ per $20 \mu \mathrm{L}$ aqueous phase, and the duration of precipitation incubation was reduced to $1 \mathrm{~h}$.

\section{Comparison between the isolation methods}

The infected serum samples (A and B), a serum sample from a healthy individual as a negative control (-ve) and an infected serum whose RNA was isolated using the kit, which showed positive in the diagnostic qRT-PCR (data not shown) as a known positive control (+ve), were subjected to the RNA isolation procedure using REC reagent, QIAamp Viral RNA Mini ${ }^{\mathrm{TM}}$ kit (QIAGEN) and REC reagent with glycogen carrier methods. The procedure was carried out on the same day for all three methods.

\section{Gel electrophoresis}

Agarose gel (2\%) in Tris-acetic acid-EDTA buffer was used to analyze the obtained RNA extracts after each method. The gel setup was prepared with DEPC water. Hence, the maintenance of a RNase-free environment was ensured. About 4 to $6 \mu \mathrm{L}$ of RNA extracts were loaded on the gel, the electrophoresis was performed for $15 \mathrm{~min}$ at $100 \mathrm{~V}$.

\section{RNA quantification}

The RNA extracts isolated from each method were quantified using a NanoDrop ${ }^{\text {TM }} 2000$ spectrophotometer (Thermo Fisher Scientific). The purity of RNA was analyzed based on 260/280 and 260/230 values for each extract. 


\section{Results}

\section{Sample collection and storage}

As detailed in the discussion section, NS1 antigen positive, IgM, and IgG antibodies negative serum samples are preferred for viral RNA isolation. Therefore, such samples were collected from the diagnostic centres and considered in the study. As the storage conditions must be appropriate for efficient RNA extraction, the collected samples were stored at $-30{ }^{\circ} \mathrm{C}$ till use.

\section{RNA isolation using GITC and TRI $I^{\mathrm{TM}}$ reagent methods}

The gel photographs of the RNA extracts isolated from infected serum samples by both GITC and TRI ${ }^{\mathrm{TM}}$ reagent methods did not show any bands except for the reference standard (insect larva) (Fig. 1), even after incorporating a modification in the protocol by increasing the duration of incubation for precipitating RNA from serum samples. Hence, the RNA extracts of infected serum samples from both methods were not considered in further analysis and the appearance of RNA bands of extracts from insect larva denied the chance of the experimental error. Ultimately, these results suggested finding an alternative method.

\section{$R N A$ isolation using $R E C$ reagent}

The gel photographs of the RNA extracts isolated using REC reagent showed the RNA bands. Among them, a few were faint, and a few others were little prominent. In Fig. 2a and $2 \mathrm{~b}$, a few lanes (lane No. corresponds to sample No.) showed a prominent RNA band below $0.5 \mathrm{~kb}$ region (lane No. 1, 7, 16, and 19), corresponding to standard reference ladder; in a few, RNA bands were just below the $1 \mathrm{~kb}$ region (lane No. 18, 20, 22, 23, 25, 26 and 27); a few showed a band near $3 \mathrm{~kb}$ (lane No. 18, 19, 20 and 22) and in rest of the lanes, bands did not appear.

\section{RNA isolation using a commercial kit}

The gel photographs of RNA (Fig. 3a and b) from infected samples extracted by the kit method showed prominent lower bands. In a few lanes, the bands were faint and in a few, lower bands appeared prominently. Improvement

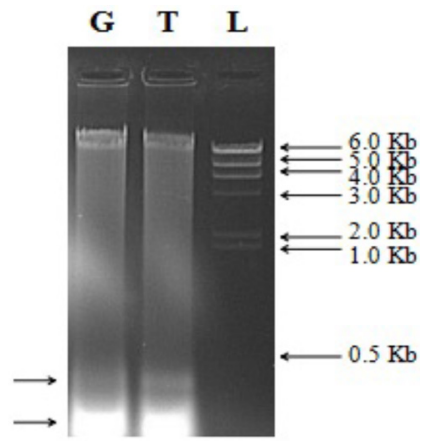

Fig. 1. Agarose gel showing the total RNA bands of insect larva (reference standard) isolated using GITC method (G) and TRI ${ }^{\mathrm{TM}}$ Reagent method $(\mathrm{T})$ along with $1 \mathrm{~Kb}$ ladder (L).

in the RNA band quality was observed when using the kit method.

\section{RNA isolation using REC reagent with glycogen carrier}

RNA-grade glycogen carrier was prepared successfully in our laboratory. For $0.5 \mathrm{~g}$ of the initial quantity of glycogen, $0.3 \mathrm{~g}$ was recovered and made use of it along with REC reagent in order to find a cost-effective alternative to the commercial kit. The quality of RNA bands obtained on the gel from this method was comparable with that of the RNA bands from the kit method and also with better concentration (Fig. $4 \mathrm{a}$ and b).

\section{Comparison between the isolation methods}

Fig. 5 shows a comparison between the RNA band qualities obtained from REC reagent, commercial kit, and REC reagent with glycogen carrier methods. The RNA from infected samples (A and B) showed prominent multiple bands, ranging between 100 to $500 \mathrm{bps}$, which is comparable with a known positive control (+ve) (qRT-PCR confirmed dengue-infected serum), whereas the negative control (ve) (healthy human serum) showed very faint bands of the same kind. The band quality and their pattern seemed to be similar using all three methods (Fig. 5a, b, and c), given that the samples were processed on the same day for all three methods. The concentration of RNA was improved
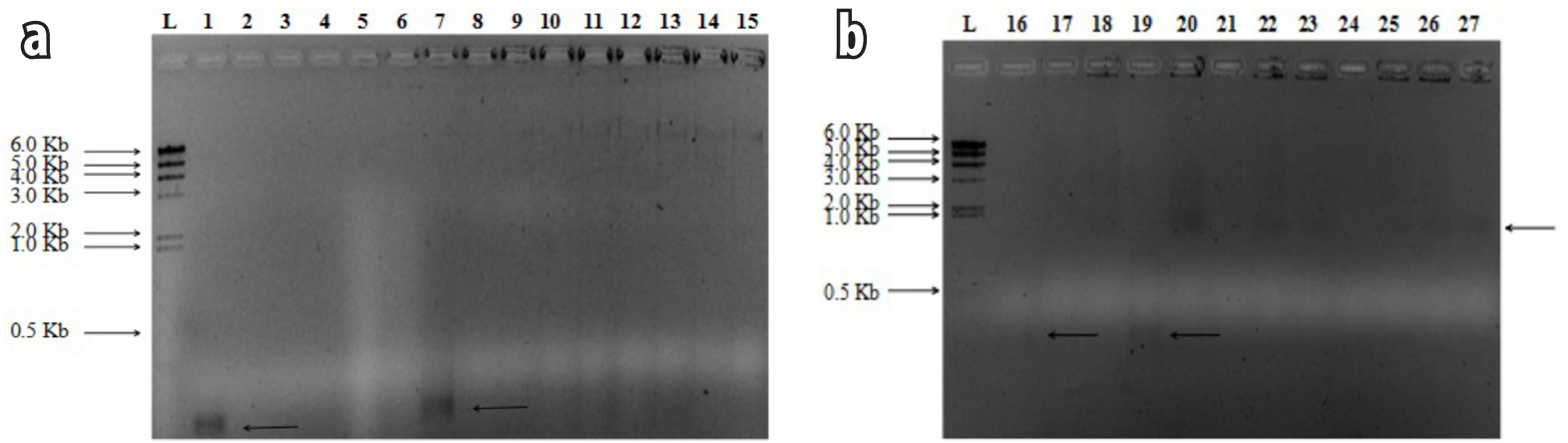

Fig. 2. Agarose gels showing the total RNA bands of extracts isolated from infected serum specimens using REC reagent (a) samples from 1 to 15 and (b) samples from 16 to 27 along with $1 \mathrm{~Kb}$ ladder (L). 

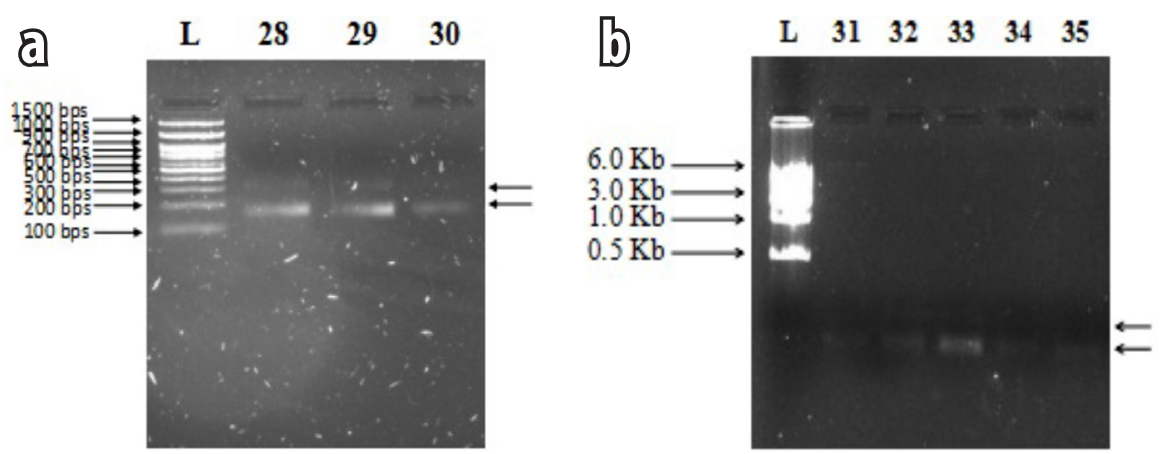

Fig. 3. Agarose gels showing the total RNA bands of extracts isolated from infected serum specimen using commercial kit (Qiagen) (a) samples from 28 to 30 with 100 bps ladder (L) and (b) samples from 31 to 35 with $1 \mathrm{~Kb}$ ladder (L).
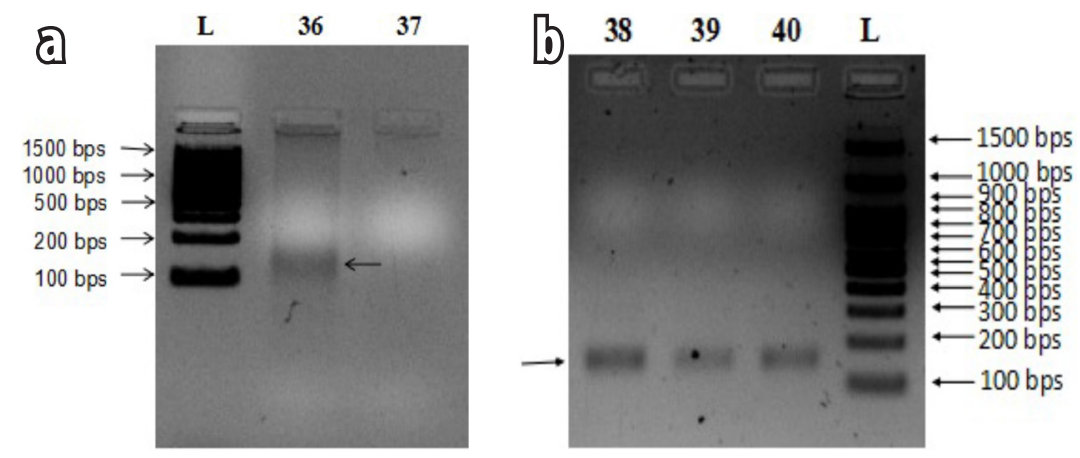

Fig. 4. Agarose gels showing the total RNA bands of extracts isolated from infected serum specimen using REC reagent with glycogen carrier (a) samples 36 and 37 (b) samples from 38 to 40 along with 100 bps ladder (L).

as noticed by more prominent bands, with the glycogen carrier compared to REC reagent alone (Fig. 5a and c). When compared between commercial kit and REC reagent with glycogen carrier methods, both gave equivalent results in terms of band quality (Fig. $5 b$ and c). Hence, this suggested that the latter method is suitable when used in a research laboratory setup dealing with many samples.

\section{RNA quantification}

The concentrations of RNA extracts of insect larva from GITC and TRI ${ }^{\mathrm{TM}}$ reagent methods were found to be 1099.9 and $944.5 \mathrm{ng} \mu \mathrm{L}^{-1}$ with purity ratios (260/280) of 3.54 and 2.93 respectively. These estimations for RNA extracts of serum samples are represented in mean \pm SD values, which are given in Table 1 . These values indicate that the average concentration of nucleic acid in the RNA extracts isolated from REC reagent seems to be high (202.94), and the average purity ratio (260/280) was much higher than 2 (3.34), whereas for that of RNA extracts isolated from the kit method the average concentration was relatively low (45.61) and the average purity ratio was a bit higher than 2 (2.51). However, extracts of RNA from REC reagent with glycogen carrier showed an average concentration relatively higher (138.88), and the average purity ratio (2.59) was almost similar to that of the kit method. The relative standard deviation values indicates both QIAGEN kit and REC reagent with glycogen carrier methods were better for concentration, all three methods were good for
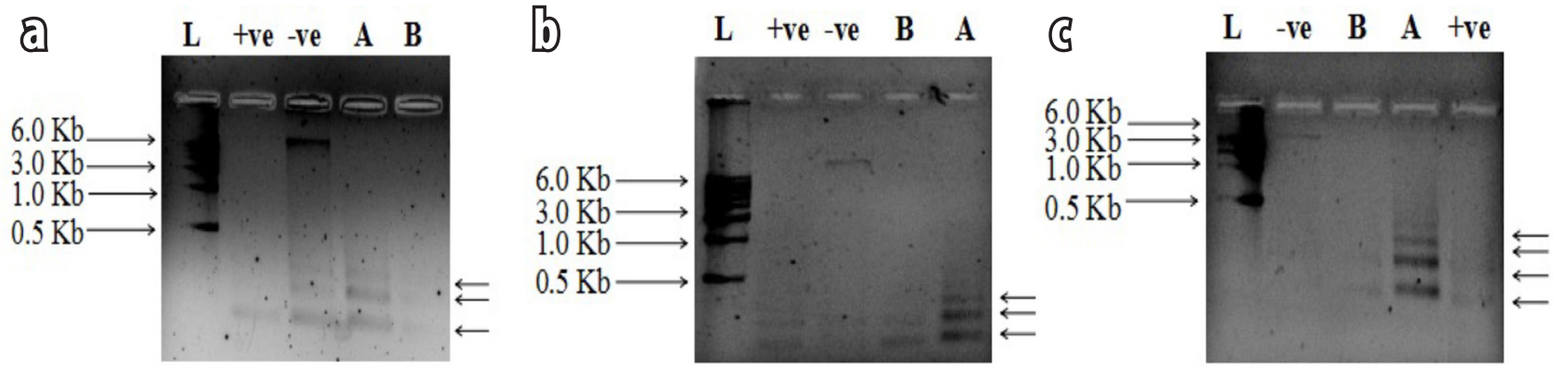

Fig. 5. Agarose gels showing the comparison of total RNA bands of extracts isolated from serum specimen using REC reagent (a) commercial kit (b) and REC reagent with glycogen carrier (c) of samples, known positive control (+ve), negative control (-ve) and infected serum specimens (A and B) along with $1 \mathrm{~Kb}$ ladder (L). 
Table 1. Values of concentration and purity ratio of RNA extracts from different isolation methods. Data are means \pm SD

\begin{tabular}{lcccccc} 
Method of isolation & \multicolumn{2}{c}{ Concentration of RNA } & \multicolumn{2}{c}{ 260/280 } & \multicolumn{2}{c}{$\mathbf{2 6 0 / 2 3 0}$} \\
\cline { 2 - 7 } & $\left(\mathbf{n g} \mu \mathrm{L}^{-1}\right)$ & RSD (\%) & (ratio) & RSD (\%) & (ratio) & RSD (\%) \\
REC reagent & $202.94 \pm 122.21$ & 60.22 & $3.35 \pm 0.18$ & 5.40 & $0.43 \pm 0.26$ & 59.30 \\
QIAGEN kit & $45.61 \pm 13.40$ & 29.37 & $2.52 \pm 0.27$ & 10.70 & $0.63 \pm 0.31$ & 49.80 \\
REC reagent with glycogen carrier & $138.88 \pm 38.42$ & 27.66 & $2.59 \pm 0.44$ & 17.02 & $1.98 \pm 0.72$ & 36.10
\end{tabular}

Table 2. Comparison between the concentration and purity ratio of RNA in the extracts among the isolation methods

\begin{tabular}{llcccc} 
Method of isolation & Quantification parameters & \multicolumn{3}{c}{ Sample } \\
\cline { 2 - 6 } & & +ve & -ve & A & B \\
\hline REC reagent & Concentration of RNA $\left(\mathrm{ng} \mu \mathrm{L}^{-1}\right)$ & 92.2 & 150.5 & 143.6 & 71 \\
& $260 / 280$ & 3.11 & 3.23 & 3.2 & 2.91 \\
& $260 / 230$ & 0.37 & 0.63 & 0.41 & 0.78 \\
\hline \multirow{2}{*}{ Qiagen kit } & Concentration of RNA $\left(\mathrm{ng} \mu \mathrm{L}^{-1}\right)$ & 65.7 & 61.5 & 112.2 & 64.1 \\
& $260 / 280$ & 2.2 & 2.16 & 2.46 & 2.24 \\
\hline REC reagent with & $260 / 230$ & 2.21 & 1.98 & 1.73 & 2.45 \\
glycogen carrier & Concentration of RNA $\left(\mathrm{ng} \mu \mathrm{L}^{-1}\right)$ & 81.4 & 70.6 & 178.4 & 74.9 \\
& $260 / 280$ & 2.32 & 2.27 & 2.8 & 2.38 \\
& $260 / 230$ & 2.39 & 2.34 & 2.56 & 2.04 \\
\hline
\end{tabular}

260/280 purity and the REC reagent with glycogen carrier method was relatively better than the other two methods for 260/230 purity. A comparison between the concentration and purity ratio of RNA extracts among the three isolation methods with same set of samples were carried out and found that the REC reagent with glycogen carrier was a better method (Table 2).

\section{Cost-effectiveness}

To ensure the cost-effectiveness of our method for viral RNA isolation, a comparison of the total expenditure for 50 reactions over the other isolation methods was verified and represented in Fig. 6, Table 3 gives supporting information. From this, it is ascertained that our method with REC reagent and glycogen carrier is approximately 16 times less costly than using the kit $\left(\right.$ QIAGEN $^{\mathrm{TM}}$ ) method and around 12 times less costly than the commercially available TRIzol $^{\mathrm{TM}}$ LS reagent. When compared with REC reagent alone, it is roughly two times more costly. This comparison gives a definite estimation of the total amount spent for each method, and our method had the edge over the others.

\section{Discussion}

In this study, isolation of total RNA having DENV genomic RNA from human serum dengue NS1 positive specimens was carried out. DENV is more prevalent during May to November, even though its occurrence is noticed throughout the year (Thanh, Giao 1996; Chareonsook et al. 1999; Morales et al. 2016; Biradar et al. 2016); this was evident during sample collection. The NS1 antigen is detected in acute phase specimens from day 3 to day 9 and rarely till day 12 from the onset of the fever, which coexists with the viremia phase where the viral RNA is present in the specimen from day 2 to day 5 and sometimes till day 7 (WHO 2009; Casenghi et al. 2018). Regular antigenantibody detection tests for dengue differentiate the samples into NS1 positive, IgM positive, and convalescent-phase samples as IgG positive (Gubler et al. 1984; Innis et al. 1989; Chanama et al. 2004; Wahala, Silva 2011). Hence, dengue NS1 positive clinical serum samples were considered for isolation of viral RNA.

The proper storage of collected samples is crucial for achieving successful isolation. As per the WHO protocol, the dengue serum specimen, for short-term storage up to $72 \mathrm{~h}$, should be kept at between 4 and $8^{\circ} \mathrm{C}$. When stored for a longer duration, the specimen should be frozen at $-70{ }^{\circ} \mathrm{C}$ or kept in a liquid nitrogen container. Few reports will also suggest that these specimens could be stored at $-20{ }^{\circ} \mathrm{C}$ for the long term with a condition of avoiding frequent freezethawing and providing a RNase free environment (Merrill et al. 2008; Peeling et al. 2010). Hence the samples were

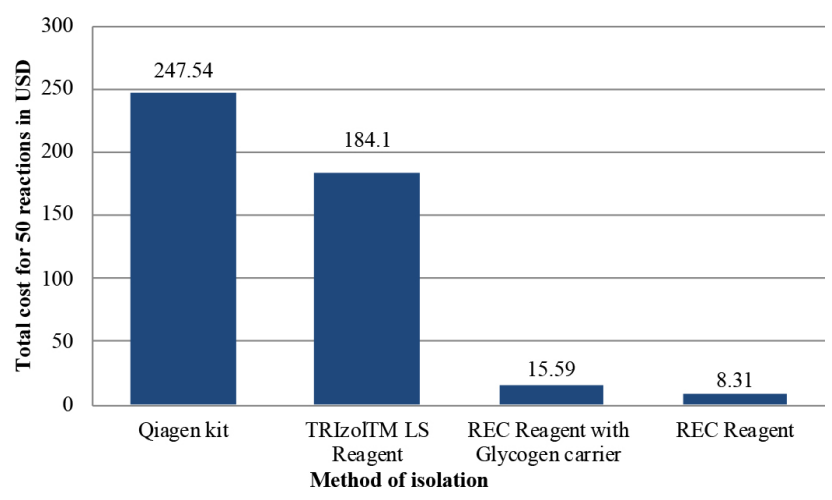

Fig. 6. The cost difference among isolation methods. 
Table 3. Product details of the chemical components used in the isolation procedure

\begin{tabular}{|c|c|c|}
\hline Components & Manufacturing company & Catalogue number \\
\hline Ammonium thiocyanate & SRL & $81016(0149153)$ \\
\hline Chloroform & Himedia & AS040 \\
\hline DEPC & Sigma & 40718 \\
\hline Ethanol & Changshu Hangsheng Fine Chemical Co. & - \\
\hline GITC & SRL & $80272(074846)$ \\
\hline Glycerol & Himedia & GRM081 \\
\hline Glycogen (from oyster) & Himedia & MB164 \\
\hline $\mathrm{HCL}$ & Himedia & AS003 \\
\hline Isoamyl alcohol & Sigma & 25666 \\
\hline Isopropanol & Himedia & AS068 \\
\hline Phenol crystalline & SRL & $14892(1649142)$ \\
\hline QIAamp Viral RNA Mini ${ }^{\mathrm{TM}}$ kit & QIAGEN & 52904 \\
\hline Sodium acetate & Sigma & 241245 \\
\hline Tris buffer & Himedia & GRM262 \\
\hline TRIzol $^{\mathrm{TM}}$ LS Reagent & Invitrogen & 10296010 \\
\hline
\end{tabular}

transported at $4{ }^{\circ} \mathrm{C}$ and stored at $-30{ }^{\circ} \mathrm{C}$ in the laboratory.

The possible reasons for the results of GITC and TRI ${ }^{\mathrm{TM}}$ Reagent methods might be the challenges associated with the residual samples and the non-suitability of the reagent or method for such samples (discussed in detail later).

Seeing the results of the REC reagent method, it was thought that the samples showing RNA bands on the gel were in the viremia phase, and the samples with no bands might have crossed that phase in which the virus circulates in the blood. Another possibility was the concentration of RNA in a few extracts was too low to be visible as bands on the gel (detailed later in this section). This also indicated that the quality of obtained RNA is not passable for further experiments.

Since the quality of RNA obtained from the REC reagent was not satisfactory, comparing the quality with a commercial kit was necessary to choose the better method for obtaining improved quality of RNA in extracts for further applications. Hence, a commercial kit was made use of. The band quality was improved in relation to the REC reagent method. While comparing the three methods, distinct lower multiple bands were observed on the gel with extracts from known positive and infected samples. A similar banding pattern in negative control samples indicated the presence of host extracellular RNA in the collected dengue-infected human serum samples. However, the human serum contains extracellular RNA molecules, as reported by a few studies (Keller et al. 2011; Danielson et al. 2017; Umu et al. 2017). The lower multiple RNA bands of infected samples probably indicate secondary structures (different conformations) formed by DENV genomic RNA, which aids in their replication, as described in the literature (Khromykh et al. 2001; You et al. 2001; Alvarez et al. 2005). In a previous study (Filomatori et al. 2017), gel pictures showing lower multiple bands were found, which represented DENV non-coding RNAs. The appearance of only a few conformations on the gel instead of multiple bands in a few samples indicated the possibility of more intactness of the appeared band conformations and very low concentration of disappeared band conformations (Fig. 3, 4 and 5).

The studies on gel analysis of other RNA viruses genomes such as influenza A (Palese, Schulman 1976) and rotavirus (Dubal et al. 2015) depict the appearance of multiple bands of their double-stranded segmented RNA genome. Another report (Nagasaki et al. 2004) describes the appearance of multiple bands by the gel analysis for the genome of a novel single strand RNA virus infecting bloom-forming diatoms, Rhizosolenia setigera. More discussion on the banding pattern of dengue RNA on the gel was not possible, because of minimal literature available in this context.

The absorbance maximum of nucleic acids is $260 \mathrm{~nm}$. The absorbance maximum ratio of $260 \mathrm{~nm}$ to that of 280 $\mathrm{nm}$ has been used from the past to measure the purity of both DNA and RNA in their extracts. Generally, pure RNA shows this ratio as $\sim 2.0$. If this ratio is lower than the standard (2.0), this indicates the presence of proteins as contaminants in the extract, whereas a low 260/230 ratio shows contamination with chemical components of the reagent used in the isolation procedure, such as phenol, guanidine, etc. If the $260 / 280$ ratio is high, that certainly does not point out any problem (Wilfinger et al. 1997). Chemical residue contaminants that remained after the extraction may contribute to the concentration of nucleic acids leading to their overestimation, negatively influencing the downstream examinations (Wilfinger et al. 1997). Based on this information, our results suggest that the higher average concentration of nucleic acids in the RNA extracts isolated from the REC reagent might indicate chemical contamination rather than the higher concentration of RNA, and a higher purity ratio of the 
same might deny protein contamination in the extracts. The relatively low RNA concentration in the extracts from the kit method perhaps shows low chemical contamination and removal of small nucleic acid molecules during the washing step in spin columns (Marko et al. 1982; Boom et al. 1990), and here, the purity ratio is almost in the standard range, hence overall reflecting the good quality of RNA.

Nevertheless, the extracts obtained from the REC reagent with glycogen carrier depicted the concentration and purity ratio in the acceptable range in relation to the kit method, indicating the contribution of glycogen as a carrier molecule in increasing the precipitation and causing the visibility of the pellet. The pellet visibility enhanced the efficiency of $75 \%$ ethanol wash, which helps decrease the chemical contamination in the extract. Glycogen, a polysaccharide acting as an inert carrier molecule/co-precipitant during the extraction of nucleic acids, improves the precipitation of RNA, which is present in low concentrations (Hengen 1996). Glycogen will not contribute to the absorption measurements acquired for concentration determinations (Fedora 2014). Altogether, the NanoDrop ${ }^{\mathrm{TM}}$ quantification analysis inferred that the REC reagent, having increased concentration of GITC and phenol along with the glycogen carrier, gave better concentration, purity (less protein contamination), and quality of RNA in the extracts.

Residual human biological materials can be defined as materials taken from the patient in a diagnostic or therapeutic procedure, which can be stored and subsequently used for research (Veen et al. 2006). There are certain challenges associated with using such samples, which were noticed in this course of the study. This includes having no knowledge of the day of sample collection from the onset of the infection in patients, as these samples are collected in a blindfold manner (without any patient information), and improper storage facilities in some collection centres add to the difficulty. These samples also largely vary in their volume and hence repetition of the experiment may not be possible. The boundaries of such de-identified leftover samples add to the technical complexity of viral RNA isolation.

Despite these drawbacks, the residual clinical specimen opens a wide opportunity for research by providing easy accessibility of clinical specimens (Wendler 2006), which will otherwise go waste. A study conducted in a hospital (Dias et al. 2019) used infected serum samples that remained after diagnosis. Still, it appears that they collected the samples in the viremia phase. In another study (De Paula et al. 2001), of one hundred suspected dengue serum samples, only six samples, whose RNA was isolated from a commercial kit (QIAamp ${ }^{\star}$ Viral RNA kit), were positive for PCR analysis. The same six samples, when their RNA were isolated using GITC (Chomczynski, Sacchi 1987) and TRIzol ${ }^{\circ}$ methods were negative for PCR analysis. This result, for instance, shows that the suitability of both sample and the method play a major role in deciding the quality of
RNA in the extracts. More studies on blindfolded leftover infected sample collection and troubleshooting the linked issues are much required, and our study is the initial step in this domain.

In our study, we used four manual methods, which were grouped under liquid phase extraction, and one commercial kit method that was spin column-based. Even though initial steps in the liquid phase (manual method) and column-based nucleic acid extraction (kit method) procedures remain the same, there are certain differences among these two, which includes more loss of the target biological material, retaining small amounts of contaminants in the final extract, difficulty in proper precipitation of low concentrated RNA, more time consuming and limited to processing few samples at a time, with the former method in relation to the latter one. The top pros and cons of different RNA extraction methods are discussed at https://lifescience.roche.comdna-and-rnapurifation. Having said that, the manual methods provide more flexibility for incorporating the modifications to enhance the performance.

As it is evident from our results, the increased concentration of the components in the REC reagent enhanced the capacity of the reagent that was lacking in the initial two methods (GITC and TRI ${ }^{\mathrm{TM}}$ reagent) for isolating diluted or low concentrated RNA in the serum samples, which was apparent on the gel with visible RNA bands. The non-suitability of those initial two methods for isolating RNA from dengue-infected serum specimens is supported by De Paula et al. (2001) report. The addition of the carrier molecule, lab-prepared glycogen, in this case, improved the RNA quality and quantity, with the same level as was achieved by the kit method. Glycogen contributed to the visibility of the pellet after precipitation, which helped process the washing step efficiently. Glycogen can be removed during $75 \%$ ethanol wash after RNA precipitation, thus reducing the chances of inhibition in downstream reactions (Fedora 2014). This proves that liquid phase extraction remains a gold standard method, as supported by previous literature (Fanson et al. 2000; Tan, Yiap 2009).

The agarose gel (2\%) electrophoresis was carried out for RNA visualization after each extraction procedure. This is a simple and routine technique in the molecular biology laboratory (Sambrook, Russel 2001). Here, it was used as a preliminary step to check the quality and to have an idea of the quantity of the obtained RNA in extracts. Electrophoresis for a shorter duration will also reduce the chance of degradation of RNA in the gel during its course of the run (Hellman, Fried 2007). Hence the gel was run only for $15 \mathrm{~min}$. It is also known that a minimum concentration of nucleic acids ( $\sim 30$ to $40 \mathrm{ng}$ ) is necessary for their bands to appear on the gel with a standard percentage (1.5 to $2 \%$ for RNA) (Hellman, Fried 2007). Therefore, the gels showing no bands does not mean that RNA extraction was not successful; it might suggest that the concentration of the obtained RNA in the extract was not enough to appear 
as bands on the gel (Hellman, Fried 2007). These results indicate that further, more sensitive experiments such as PCR with virus-specific primers, are required to analyze the successful viral RNA extraction (Lanciotti et al. 1992; Anoop et al. 2010; Ahamed et al. 2017). However, agarose gel, even with certain limitations, acts as a simple and basic platform by providing information on the quality, integrity, and quantity of RNA to take it forward for downstream experiments (Aranda et al. 2012). Also, it was found that there are not many or extremely few, which are even equal to none, gel pictures showing the bands of dengue viral RNA genome in the literature (Filomatori et al. 2017). Therefore, in this study, agarose gel was used as a cost-effective primary analytical method for obtained RNA extracts, and this may serve as a reference for future studies to visualize dengue genomic RNA bands. A study previously reported the use of viral genomic RNA banding patterns for early and rapid diagnosis of the disease (Dubal et al. 2015). More detailed studies on the banding pattern of dengue genomic RNA may even serve as a tool for its diagnosis, considering it as a future aspect.

It is evident from this study, that to work cost-effectively during research involving the processing of a number of samples; one can adapt and standardize manual methods instead of using kits, which are very expensive. A manual method using REC reagent, for liquid samples containing RNA in low concentration, proved to be efficient along with the co-precipitant glycogen for isolating total RNA from blindfolded dengue-infected clinical serum specimens with reasonable consistency in results. Considering the importance of gel analysis, serving as a reference for banding patterns, detailed studies in this area might contribute to the diagnostic aspect in the future.

In centres for disease control and prevention guidelines, the recommended biosafety level for all four serotypes of the DENV is BSL-2. All activities involving handling dengue specimens were carried out inside the biosafety cabinet with proper precautions and care taken during the usage and disposal of the consumables that had come in contact with the specimen by treating them with $0.1 \%$ sodium hypochlorite solution and autoclaving.

\section{Acknowledgements}

We are thankful to Dr. Chandrakanth Kelmani R., Professor, Department of Biotechnology, Gulbarga University, Kalburgi; and Dr. Ambica R., Professor \& Head; and Dr. Shantala G.B., Professor, Department of Microbiology; and State level Virus Research and Diagnostic Laboratory team, Bangalore Medical College and Research Institute, Bengaluru, for providing, space, facility and timely guidance to carry out the isolation procedure; Dr. R. Nagesh Babu, Associate Professor, Department of Biochemistry, Maharani Science College for Women, Bengaluru, for providing the NanoDrop ${ }^{\mathrm{TM}}$ facility and the diagnostic centres, which provided the serum specimens. Authors declare no conflict of interest.

\section{References}

Ahamed S.F., Vivek R., Kotabagi S., Nayak K., Chandele A., Kaja M.K., Shet A. 2017. Enhancing the sensitivity of Dengue virus serotype detection by RT-PCR among infected children in India. J. Virol. Methods 244: 46-54.

Alvarez D.E., Lodeiro M.F., Luduena S J., Pietrasanta L.I., Gamarnik A.V. 2005. Long-range RNA-RNA interactions circularize the dengue virus genome. J. Virol. 79: 6631.

Anoop M., Issac A., Mathew T., Philip S., Kareem N.A., Unnikrishnan R., Sreekumar E. 2010. Genetic characterization of dengue virus serotypes causing concurrent infection in an outbreak in Ernakulam, Kerala, South India. Indian J. Exp. Biol. 48: 849-857.

Anwar A., Wan G., Chua K.B., August J.T., Too H.P. 2009. Evaluation of pre-analytical variables in the quantification of dengue virus by real-time polymerase chain reaction. J. Mol. Diagn. 11: 537-542.

Aranda P.S., LaJoie D.M., Jorcyk C.L. 2012. Bleach gel: a simple agarose gel for analyzing RNA quality. Electrophoresis 33: 366-369.

Bhatt S., Gething P.W., Brady O.J., Messina J.P., Farlow A.W., Moyes C.L., Hay S.I. 2013. The global distribution and burden of dengue. Nature 496: 504-507.

Biradar A., Kauser Y., Itagi I., Jamadar N.A. 2016. Dengue infection: its prevalence with seasonal variations. Indian $J$ Microbiol Res. 3: 89-92.

Boom R.C.J.A., Sol C.J., Salimans M.M., Jansen C.L., Wertheimvan Dillen P M., Van der Noordaa J.P.M.E. 1990. Rapid and simple method for purification of nucleic acids. J. Clin. Microbiol. 28: 495-503.

Brady O. 2019. Disease risk: mapping the emerging burden of dengue. eLife 8: e47458.

Brady O.J., Gething P.W., Bhatt S., Messina J.P., Brownstein J.S., Hoen A.G., Hay S.I. 2012. Refining the global spatial limits of dengue virus transmission by evidence-based consensus. PLoS Negl. Trop. Dis. 6: e1760.

Brooks G. 1998. Biotechnology in Healthcare: An Introduction to Biopharmaceuticals. Pharmaceutical Press, London.

Buckingham L., Flaws M.L. 2007. Molecular Diagnostics: Fundamentals, Methods and Clinical Applications. F.A. Davis Company, Philadelphia.

Casenghi M., Kosack C., Li, R., Bastard M., Ford N. 2014. NS1 antigen detecting assays for diagnosing acute dengue infection in people living in or returning from endemic countries. Cochrane Database Syst. Rev. 6: CD011155.

CDC 2010. Locally acquired dengue - Key West, Florida, 20092010. Morb. Mortal. Weekly Rep. 59: 577-581.

Chanama S., Anantapreecha S., A-nuegoonpipat A., Sa-gnasang A., Kurane I., Sawanpanyalert P. 2004. Analysis of specific IgM responses in secondary dengue virus infections: levels and positive rates in comparison with primary infections. J. Clin. Virol. 31: 185-189.

Chareonsook O., Foy H.M., Teeraratkul A., Silarug N. 1999. Changing epidemiology of dengue hemorrhagic fever in Thailand. Epidemiol. Infect. 122: 161-166.

Chen H.L., Lin S.R., Liu H.F., King C.C., Hsieh S.C., Wang W.K. 2008. Evolution of dengue virus type 2 during two consecutive outbreaks with an increase in severity in southern Taiwan in 2001-2002. Am. J. Trop. Med. Hyg. 79: 495-505.

Chomczynski P., Mackey K. 1995. Short technical reports. Modification of the TRI reagent procedure for isolation of 
RNA from polysaccharide-and proteoglycan-rich sources. Biotechniques 19: 942-945.

Chomczynski P., Sacchi N. 1987. Single-step method of RNA isolation by acid guanidinium thiocyanate-phenolchloroform extraction. Anal. Biochem. 162: 156-159.

Chomczynski P., Sacchi N. 2006. The single-step method of RNA isolation by acid guanidinium thiocyanate-phenolchloroform extraction: twenty-something years on. Nat. Protoc. 1: 581-585.

Dahm R. 2005. Friedrich Miescher and the discovery of DNA. Dev. Biol. 278: 274-288.

Danielson K.M., Rubio R., Abderazzaq F., Das S., Wang Y.E. 2017. High throughput sequencing of extracellular RNA from human plasma. PLoS One 12: e0164644.

Darwish N.T., Alias Y.B., Khor S.M. 2015. An introduction to dengue-disease diagnostics. TrAC Trends Analyt. Chem. 67: 45-55.

De Paula S.O., Nunes C., Matos R., de Oliveira Z.M., Lima D.M., da Fonseca B.A.L. 2001. Comparison of techniques for extracting viral RNA from isolation-negative serum for dengue diagnosis by the polymerase chain reaction. J. Virol. Methods 98: 119-125.

Dettogni R.S., Louro I.D. 2011. Dengue virus RNA purification from human plasma: a comparison of two techniques. Mol. Biol. Rep. 38: 4979-4983.

Dias M., Pattabiraman C., Siddappa S., Gowda M., Shet A., Smith D., Krishna S. 2019. Complete assembly of a dengue virus type 3 genome from a recent genotype III clade by metagenomic sequencing of serum. Wellcome Open Res. 3: 3339-3349.

Domingo C., Patel P., Linke S., Achazi K., Niedrig M. 2011. Molecular diagnosis of flaviviruses. Future Virol. 6: 10591074.

Doyle K. 1996. The Source of Discovery: Promega Protocols and Applications Guide. Promega Corporation, Madison.

Dubal Z.B., Mawlong M., Susngi B., Sanjukta R., Puro K., Ghatak S., Bhattacharjee U. 2015. Comparison of agarose gel electrophoresis and RNA-PAGE for rapid detection of rotavirus from faecal samples. J. Appl. Anim. Res. 43: 77-82.

Fan H. 2006. Homemade Glycogen (Molecular Biology Grade) for DNA/RNA Precipitation. http://boneandcancer.org/_st atic/7e9e0ed84527222221658892b38040d7/a41-homemademb-grade-glycogen(2).pdf?dl=1 /last accessed December 15, 2021/

Fanson B.G., Osmack P., Di Bisceglie A.M. 2000. A comparison between the phenol-chloroform method of RNA extraction and the QIAamp viral RNA kit in the extraction of hepatitis $\mathrm{C}$ and GB virus-C/hepatitis G viral RNA from serum. J. Virol. Methods 89: 23-27.

Filomatori C.V., Carballeda J.M., Villordo S.M., Aguirre S., Pallares H.M., Maestre A.M., Gamarnik A.V. 2017. Dengue virus genomic variation associated with mosquito adaptation defines the pattern of viral non-coding RNAs and fitness in human cells. PLoS Pathog. 13: e1006265.

Ganeshkumar P., Murhekar M.V., Poornima V., Saravanakumar V., Sukumaran K., Anandaselvasankar A., Mehendale S.M. 2018. Dengue infection in India: A systematic review and meta-analysis. PLoS Negl. Trop. Dis. 12: e0006618.

Gubler D.J., Kuno G., Sather G.E., Velez M., Oliver A.N.D.A. 1984. Mosquito cell cultures and specific monoclonal antibodies in surveillance for dengue viruses. Am. J. Trop. Med. Hyg. 33: 158-165.

Halstead S.B. 1970. Observations related to pathogenesis of dengue hemorrhagic fever. VI. Hypotheses and discussion. Yale J. Biol. Med. 42: 350-362.

Hellman L.M., Fried M.G. 2007. Electrophoretic mobility shift assay (EMSA) for detecting protein-nucleic acid interactions. Nat. Protoc. 2: 1849.

Hengen P.N. 1996. Methods and reagents - Carriers for precipitating nucleic acids. Trends Biochem. Sci. 21: 224-225.

Houldcroft C.J., Beale M.A., Breuer J. 2017. Clinical and biological insights from viral genome sequencing. Nat. Rev. Microbiol. 15: 183-192.

Howard C.R. Fletcher N.F. 2012. Emerging virus diseases: can we ever expect the unexpected? Emerg. Microbes Infect. 1: 1-9.

Innis B.L., Nisalak A., Nimmannitya S., Kusalerdchariya S., Chongswasdi V., Suntayakorn S., Hoke C.H. 1989. An enzyme-linked immunosorbent assay to characterize dengue infections where dengue and Japanese encephalitis cocirculate. Am. J. Trop. Med. Hyg. 40: 418-427.

Keller A., Leidinger P., Gislefoss R., Haugen A., Langseth H., Staehler P., Meese E. 2011. Stable serum miRNA profiles as potential tool for non-invasive lung cancer diagnosis. RNA Biol. 8: 506-516.

Khromykh A.A., Meka H., Guyatt K.J., Westaway E.G. 2001. Essential role of cyclization sequences in flavivirus RNA replication. J. Virol. 75: 6719.

Klungthong C., Gibbons R.V., Thaisomboonsuk B., Nisalak A., Kalayanarooj S., Thirawuth V., Jarman R.G. 2007. Dengue virus detection using whole blood for reverse transcriptase PCR and virus isolation. J. Clin. Microbiol. 45: 2480-2485.

Lanciotti R.S., Calisher C.H., Gubler D.J., Chang G.J., Vorndam A.V. 1992. Rapid detection and typing of dengue viruses from clinical samples by using reverse transcriptase-polymerase chain reaction. J. Clin. Microbiol. 30: 545-551.

Mabey D., Peeling R.W., Ustianowski A., Perkins M.D. 2004. Diagnostics for the developing world. Nat. Rev. Microbiol. 2: 231-240.

Margam V.M., Gachomo E.W., Shukle J.H., Ariyo O.O., Seufferheld M.J., Kotchoni S.O. 2010. A simplified arthropod genomicDNA extraction protocol for polymerase chain reaction (PCR)-based specimen identification through barcoding. Mol. Biol. Rep. 37: 3631-3635.

Marko M.A., Chipperfield R., Birnboim H.C. 1982. A procedure for the large-scale isolation of highly purified plasmid DNA using alkaline extraction and binding to glass powder. Anal. Biochem. 121: 382-387.

Merrill D.R., Wade C.D., Fahnestock P., Baker R.O. 2018. Long-term and short-term stability of viruses depend on storage temperature and preservation method. https://www. beiresources.org/Portals/2/PDFS/Long-Term $\% 20$ and $\% 20$ Short-Term\%20Stability\%20of\%20Viruses.pdf. /last accessed December 15, 2021/

Mohamed N. 2006. Molecular Diagnosis of Common Viral Infectious Diseases Based on Real-Time PCR. Doctoral dissertation, Acta Universitatis Upsaliensis.

Montecillo-Aguado M.R., Montes-Gomez A.E., Garcia-Cordero J., Corzo-Gomez J., Vivanco-Cid H., Mellado-Sanchez G., Cedillo-Barron L. 2019. Cross-reaction, enhancement, and neutralization activity of dengue virus antibodies against zika virus: a study in the Mexican population. J. Immunol. Res. 2019: 7239347.

Morales I., Salje H., Saha S., Gurley E.S. 2016. Seasonal distribution and climatic correlates of dengue disease in Dhaka, Bangladesh. Am. J. Trop. Med. Hyg. 94: 1359-1361. 
Mukhtar M. 2015. Bacterial and viral infections impact on human health. EC Bacteriol. Virol. Res. 1: 1-4.

Murray N.E.A., Quam M.B., Wilder-Smith A. 2013. Epidemiology of dengue: past, present and future prospects. Clin. Epidemiol. 5: 299.

Nagasaki K., Tomaru Y., Katanozaka N., Shirai Y., Nishida K., Itakura S., Yamaguchi M. 2004. Isolation and characterization of a novel single-stranded RNA virus infecting the bloomforming diatom Rhizosolenia setigera. Appl. Environ. Microbiol. 70: 704-711.

Neeraja M., Lakshmi V., Lavanya V., Priyanka E.N., Parida M.M., Dash P.K., Reddy G. 2015. Rapid detection and differentiation of dengue virus serotypes by NS1 specific reverse transcription loop-mediated isothermal amplification (RT-LAMP) assay in patients presenting to a tertiary care hospital in Hyderabad, India. J. Virol. Methods 211: 22-31.

Palese P., Schulman J.L. 1976. Differences in RNA patterns of influenza A viruses. J. Virol. 17: 876-884.

Palmares A.J.S., Chan V.F., Baclig M.O. 2017. Comparison of techniques for extracting viral RNA in plasma for dengue diagnosis by reverse transcriptase-PCR. Asian J. Biol. Sci. 6: 3.

Patel P., Landt O., Kaiser M., Faye O., Koppe T., Lass U., Niedrig M. 2013. Development of one-step quantitative reverse transcription PCR for the rapid detection of flaviviruses. Virol. J. 10: 1-11.

Peeling R.W., Artsob H., Pelegrino J.L., Buchy P., Cardosa M.J., Devi S., Yoksan S. 2010. Evaluation of diagnostic tests: dengue. Nat. Rev. Microbiol. 8: S30-S37.

Pekosz A., Glass G. E. 2008. Emerging viral diseases. Maryland Med. 9: 11.

Rathore A.P., St. John A.L. 2020. Cross-reactive immunity among flaviviruses. Front. Immunol. 11: 334.

Reynes J.M., Ong S., Mey C., Ngan C., Hoyer S., Sall A.A. 2003. Improved molecular detection of dengue virus serotype 1 variants. J. Clin. Microbiol. 41: 3864.

Salvi R. 2004. How to prepare Molecular Biology grade glycogen. Protocols Online. http://www.protocol-online.org/cgibin/prot/page.cgi?g=print_page/1902.html. /last accessed December 15, 2021/

Sambrook J., Russell D.W. 2001. Molecular Cloning: A Laboratory Manual. Vol 3. Cold Spring Harbour Laboratory Press, New York.

Sutton F. 2014. Can anyone assist with the best RNA carrier? https://www.researchgate.net/post/Can_anyone_assist_with_ the_best_RNA_carrier. /last accessed December 15, 2021/
Tan S.C., Yiap B.C. 2009. DNA, RNA, and protein extraction: the past and the present. J. Biomed. Biotechnol. 2009: 574398.

Tang Y.W., Procop G.W. Persing D.H. 1997. Molecular diagnostics of infectious diseases. Clin. Chem. 43: 2021-2038.

Thanh N., Giao P. 1996. Epidemiology and clinical feature findings of dengue haemorrhagic fever in Ho Chi Minh city and Centre for Tropical Diseases-Vietnam. Trop. Med. 36: 177-186.

Tsai J.J., Liu W. L., Lin P.C., Huang B.Y., Tsai C.Y., Lee P.Y.A., Chen C.H. 2019. A fully automated sample-to-answer PCR system for easy and sensitive detection of dengue virus in human serum and mosquitos. PLoS One 14: e0218139.

Ullrich A., Shine J., Chirgwin J., Pictet R., Tischer E., Rutter W.J., Goodman H.M. 1977. Rat insulin genes: construction of plasmids containing the coding sequences. Science 196: 1313-1319.

Umu S.U., Langseth H., Bucher-Johannessen C., Fromm B., Keller A., Meese E., Rounge T. B. 2018. A comprehensive profile of circulating RNAs in human serum. RNA Biol. 15: 242-250.

Van Veen E. B., Riegman P.H.J., Dinjens W.N.M., Lam K.H., Oomen M.H.A., Spatz A., Oosterhuis J.W. 2006. TuBaFrost 3: regulatory and ethical issues on the exchange of residual tissue for research across Europe. Eur. J. Cancer 42: 2914-2923.

WHO. 2009. Dengue: guidelines for diagnosis, treatment, prevention and control. WHO/HTM/NTD/ DEN/2009.1. World Health Organization.

Wahala W.M., De Silva A.M. 2011. The human antibody response to dengue virus infection. Viruses 3: 2374-2395.

Wendler D. 2006. One-time general consent for research on biological samples: is it compatible with the health insurance portability and accountability act? Arch. Intern. Med. 166: 1449-1452.

Wilfinger W.W., Mackey K., Chomczynski P. 1997. Effect of pH and ionic strength on the spectrophotometric assessment of nucleic acid purity. Biotechniques 22: 474-481.

Woolhouse M., Scott F., Hudson Z., Howey R., Chase-Topping M. 2012. Human viruses: discovery and emergence. Philos. Trans. R. Soc. London B Biol. Sci. 367: 2864-2871.

Xiang X., Qiu D., Hegele R.D., Tan W.C. 2001. Comparison of different methods of total RNA extraction for viral detection in sputum. J. Virol. Methods 94: 129-135.

You S., Falgout B., Markoff L., Padmanabhan R. 2001. In vitro RNA synthesis from exogenous dengue viral RNA templates requires long range interactions between 5'-and 3'-terminal regions that influence RNA structure. J. Biol. Chem. 276: 15581-15591. 